\title{
Cytokine-Modulatory Activity and Therapeutic Efficacy of 7-Amino-4- Methylcoumarin in Murine Collagen-Induced Arthritis
}

\author{
Masahiko Kurokawa, ${ }^{\mathrm{a}, *}$, Masami Imakita ${ }^{\mathrm{b}}$ and Kimiyasu Shiraki ${ }^{\mathrm{c}}$ \\ ${ }^{a}$ Department of Biochemistry, School of Pharmaceutical Sciences, Kyushu University of Health and Welfare, 1714-1 \\ Yoshino, Nobeoka, Miyazaki 882-8508, Japan, ${ }^{b}$ Department of Pathology, Rinku General Medical Center, Izumisano, \\ Osaka, 598-8577 Japan, 'Department of Virology, University of Toyama, 2630 Sugitani, Toyama 930-0194, Japan
}

\begin{abstract}
Amino-4-methylcoumarin (AMC) was previously shown to suppress pro-inflammatory cytokine production and prevent death in an endotoxic shock model in mice. In the present study, we investigated the effectiveness of AMC as a potential cytokine modulator in alleviating autoimmune diseases. We examined the efficacy and cytokine-modulatory activity of AMC in collagen-induced arthritis (CIA) in mice. Mice were immunized with type II collagen. AMC at 0, 3, or $30 \mathrm{mg} / \mathrm{kg}$ was administered orally to the immunized mice once daily for three weeks before and/or three times daily for two weeks after the onset of CIA. The development of arthritis of the paws and cytokine levels in serum were examined. AMC significantly reduced the incidence and severity of CIA prophylactically and therapeutically, and suppressed the rise of systemic interleukin- 6 and interferon- $\gamma$ levels to the basal levels in the early phase of CIA. AMC also significantly suppressed the level of tumor necrosis factor- $\alpha$ in the severe phase of CIA. However, the levels of interleukin-10 and anti-collagen antibody were not affected by AMC. In the early phase of CIA, the suppression of interleukin-6 and interferon- $\gamma$. levels by AMC correlated with the amelioration of symptoms of CIA in a dose-dependent manner. AMC may inhibit the onset of cytokine-mediated disease rather than suppressing disease progression without toxicity or affecting anti-collagen antibody production. AMC was significantly effective against CIA in mice and confirmed to possess cytokine-modulatory activity in vivo. The results suggest that AMC is a potential therapeutic agent for autoimmune diseases.
\end{abstract}

Keywords: Collagen-induced arthritis, 7-amino-4-methylcoumarin, cytokines.

\section{INTRODUCTION}

Cytokines play important roles in modulating immune responses and influence the establishment of host-defense system against infection. They also have primary roles directly or indirectly in the pathogenesis of inflammatory and autoimmune diseases [1-6]. Thus, the modification of cytokine production in cytokine-mediated diseases may contribute to the understanding of their pathogenesis and provide information to improve the treatment of cytokine-mediated diseases.

We have been studying the roles of traditional medicines in modification of the course of viral infection by assessing antiviral activity and cytokine levels [7-13]. Cinnamyl derivatives and related compounds originating from herbal medicines were demonstrated to possess antipyretic activity by suppressing the rise of interleukin (IL)- $1 \alpha$ production subsequent to the interferon (IFN)- $\alpha$ production that was induced by influenza infection in mice [7-9]. The cinnamyl derivatives were suggested to contribute to the modification of cytokine production and alleviation of infection without affecting basal cytokine levels. Among these compounds, 7amino-4-methylcoumarin (AMC), a semisynthetic derivative

*Address correspondence to this author at Department of Biochemistry, School of Pharmaceutical Sciences, Kyushu University of Health and Welfare, 1714-1 Yoshino, Nobeoka, Miyazaki 882-8508, Japan; Tel: +81-98223-5574; Fax: +81-982-23-5684; E-mail: b2mk@phoenix.ac.jp of coumarin, prevented death without toxicity in an endotoxic shock model in mice and suppressed the rise in levels of systemic pro-inflammatory cytokines, such as tumor necrosis factor (TNF)- $\alpha$, without affecting basal cytokine levels [13]. AMC was suggested to be a potential cytokine modulator.

Collagen-induced arthritis (CIA) in mice has been used as a model of inflammatory polyarthritis with similarities to rheumatoid arthritis (RA) to evaluate the importance of the inflammatory cytokines [14]. Anti-cytokine therapy for RA [15] and analysis of IL-6-deficient mice [16,17] showed that pro-inflammatory cytokines are important mediators of the pathogenic process. This murine model is also useful to evaluate the in vivo cytokine-modulatory activity of AMC and its therapeutic efficacy. Thus, in this study, to evaluate the potential of AMC for the treatment of autoimmune diseases, we examined its cytokine-modulatory and therapeutic activities in a CIA model.

\section{MATERIALS AND METHODOLOGY}

Mice

Female DBA/1 mice (7-week-old, 15-17 g, Charles River, Yokohama, Japan) were housed 5 per cage at $23 \pm 2{ }^{\circ} \mathrm{C}$ with food and pyrogen-free water ad libitum and under a 12 $\mathrm{h}$ light/12 h dark diurnal cycle (light at 7.00 a.m.). The mice were acclimated for at least 5 days before starting an ex- 
perimental procedure. The experimental protocols were approved by the Animal Experiment Committee of University of Toyama and Kyushu University of Health and Welfare, Japan, and their animal experimentation guidelines were followed in the animal studies.

\section{Compound}

AMC (purity, 99\%; Sigma, St. Louis, MO, USA, Fig. 1) was suspended in 5\% gum arabic and orally administered to mice. As a control, $5 \%$ gum arabic was used.<smiles>Cc1cc(=O)oc2cc(N)ccc12</smiles>

Fig. (1). Chemical structure of AMC.

\section{CIA Model in Mice}

The efficacy and cytokine-modulatory activity of AMC were examined in a CIA model in mice. DBA/1 mice were primed by an intradermal injection of $0.2 \mathrm{ml}$ of an emulsion consisting of equal volumes of Freund's complete adjuvant (Difco, Detroit, MI, USA) and 2\% bovine collagen type II (Elastin Products, Owensville, MO, USA) dissolved in $0.1 \mathrm{M}$ acetic acid [18]. Three weeks later, the mice were boosted intradermally with the same amount of the emulsion. AMC administration was prophylactically and therapeutically performed before and after, respectively, the onset of arthritis when swelling of the paws was initially observed. In the case of prophylactic administration, $\mathrm{AMC}$ at 0,3 , or $30 \mathrm{mg} / \mathrm{kg}$ was administered orally once daily for three weeks after priming and then three times daily for two weeks after the booster. In the case of therapeutic AMC administration, $\mathrm{AMC}$ at 0 or $30 \mathrm{mg} / \mathrm{kg}$ was administered to immunized mice for one week from day 27 after the onset of arthritis. Mock-immunized mice $(\mathrm{n}=5)$ were administered $\mathrm{AMC}$ at 0 or $30 \mathrm{mg} / \mathrm{kg}$ in the same manner as immunized mice to evaluate the toxicity of AMC. Each mouse was weighed daily after the booster. Each paw was assessed once daily for development of arthritis and scored simultaneously at least by two persons as: 0 , no swelling; 1 , swelling of one or two toes or slight swelling of the ankles; 2, swelling of one or two toes accompanied by slight or moderate swelling of the ankles; or 3, extensive swelling of the paws. The score of each mouse was expressed as the sum of the scores for four paws [18].

For joint-degeneration analysis, the paws of 6 mice in each group were extirpated at about $8 \mathrm{~mm}$ above the wrist and ankle joints after exsanguination, and the paws were weighed on day 35 after priming. Forty-two joints per mouse, the forepaw carpus, five metacarpals, and four proximal phalanges (2nd to 5 th) and the hindpaw calcaneus, tarsus, five metacarpals, and four proximal phalanges (2nd and 5th) were subjected to radiographic analysis [18]. The numbers of degenerated joints were determined. The paws were fixed in buffered formalin and decalcified in 5\% EDTA. The paws were subsequently embedded in paraffin, sectioned, stained with hematoxylin and eosin, and analyzed histologically.

\section{Enzyme-Linked Immunosorbent Assay (ELISA) of Serum}

On days 27,31 , and 41 after priming, serum was drawn from 4 to 7 mice in each group, and the concentrations of cytokines (IL-6, IL-10, IFN- $\gamma$, and TNF- $\alpha$ ) were determined using ELISA kits (Amersham Pharmacia Biotech, Buckinghamshire, England, or BioSource, Camarillo, CA) according to the manufacturer's instructions. Detection sensitivities of the kits were IL-6, $4 \mathrm{pg} / \mathrm{ml}$; IL-10, $30 \mathrm{pg} / \mathrm{ml}$; IFN- $\gamma, 0.7$ $\mathrm{pg} / \mathrm{ml}$; and TNF- $\alpha, 8 \mathrm{pg} / \mathrm{ml}$.

In addition, the amount of anti-collagen type II antibody in serum from 5 mice in each group on days 27, 31, and 41 after priming was determined by an ELISA method as described previously [19]. Briefly, 96-well microtiter plates were coated with $50 \mu \mathrm{l}$ of collagen type II at $200 \mu \mathrm{g} / \mathrm{ml}$ in phosphate-buffered saline (PBS) overnight at $4{ }^{\circ} \mathrm{C}$. The plates were washed with PBS and blocked with $3 \%$ skim milk in PBS, and then sera diluted with PBS $(100 \mu l)$ were incubated at $37^{\circ} \mathrm{C}$ for $1 \mathrm{~h}$. Wells were washed extensively and incubated with peroxidase-conjugated rabbit anti-mouse immunoglobulin (DAKO A/S, Denmark) for $1 \mathrm{~h}$ at $37^{\circ} \mathrm{C}$. After washes with PBS, the enzyme reaction was performed and the absorbance of the reaction mixture was measured at 490 nm.

\section{Statistical Analyses}

Student's $t$-test was used to evaluate the significance of the differences in mean cytokine levels on days examined, mean weights of paws, numbers of degenerated joints, and mean absorbances at $490 \mathrm{~nm}$ for anti-collagen IgG. A repeated measures two-way ANOVA (RM-ANOVA) was used to analyze the interaction between mean scores in treated and control groups for 15 days after the second immunization. Statistical differences in the incidences of collagen-induced arthritis were evaluated using Fischer's exact test. A $p$-value of less than 0.05 was statistically defined as significant.

\section{RESULTS \\ Efficacy of AMC on CIA}

We evaluated the efficacy of AMC in a CIA model in $\mathrm{DBA} / 1$ mice. In collagen-immunized mice, mild inflammatory arthritis affecting either the toes or metatarsophalangeal joints had developed by 26 days post-priming, and severe deforming arthritis was observed within 35 days of priming. In histological analysis of the joints, the immunized mice without AMC administration exhibited inflammatory cell infiltrate with prominent pannus formation on day 41 , and the joint space was filled with granulation tissue compared with mock-immunized mice without AMC administration (Fig. 2A and B). Further, the articular cartilage had disappeared, and granulation tissue had grown into the subchondral marrow of the bone. However, the immunized mice with AMC administration showed minimal pannus formation, and the articular cartilage was relatively well preserved (Fig. 2C and D). Our clinical assessments were confirmed histologically.

Prophylactic and therapeutic administration of AMC at $30 \mathrm{mg} / \mathrm{kg}$ significantly reduced the incidence of CIA compared with $\mathrm{AMC}$ at $0 \mathrm{mg} / \mathrm{kg}(p<0.05$, Table 1). AMC at 30 


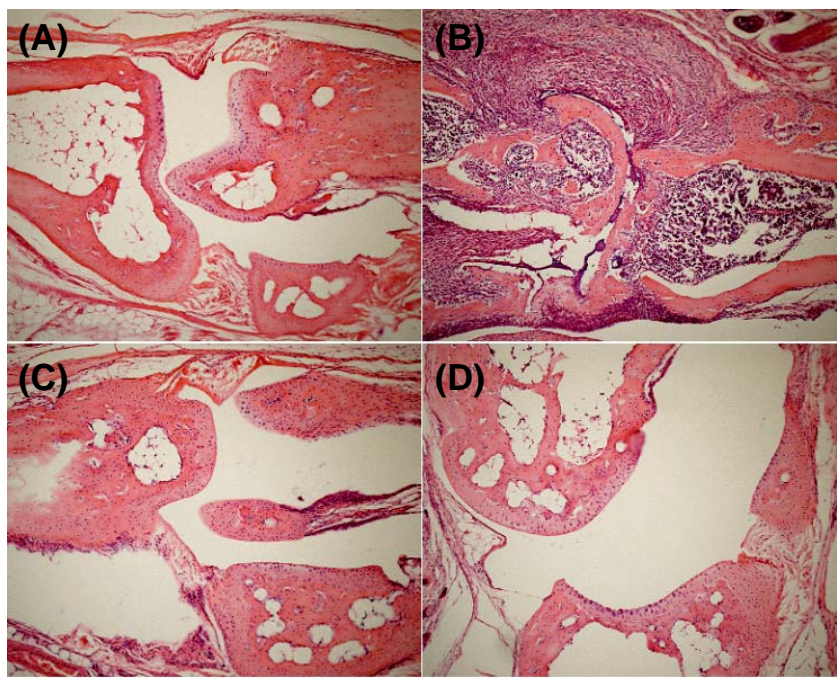

Fig. (2). Effect of AMC administration on histological features of joints from collagen-immunized mice. (A), mock-immunized mice without AMC administration. (B), immunized mice without AMC administration. (C), immunized mice with AMC administration at $3 \mathrm{mg} / \mathrm{kg}$. (D), immunized mice with AMC administration at 30 $\mathrm{mg} / \mathrm{kg}$.

$\mathrm{mg} / \mathrm{kg}$ was significantly effective in reducing the total weight of the four paws and the amount of joint degeneration on day 35 ( $p<0.05$ and 0.005 , respectively, Table 1). The development of CIA was significantly retarded by AMC at 3 and $30 \mathrm{mg} / \mathrm{kg}$ in a dose-dependent manner $(p<0.02$ and 0.002 , respectively, Fig. 3A). The significant reductions in the incidence and retardation of CIA by AMC at $30 \mathrm{mg} / \mathrm{kg}$ were confirmed by repeated experiments. There was no significant difference between the mean weights of mockimmunized mice administered AMC at 0 and $30 \mathrm{mg} / \mathrm{kg}$ once daily for three weeks and three times daily for two weeks $(18.3 \pm 0.3 \mathrm{~g}$ and $17.6 \pm 0.4 \mathrm{~g}$, respectively). No significant difference in the amounts of anti-collagen IgG in sera on days 27, 31, and 41 was found in mice treated with and without $\mathrm{AMC}$ at $30 \mathrm{mg} / \mathrm{kg}$ (Table 1), although there was a trend for anti-collagen IgG to decrease in AMC-administered CIA mice. Further, therapeutic administration of AMC at 30 $\mathrm{mg} / \mathrm{kg}$ from the onset of mild inflammatory arthritis (day 27) significantly reduced the progression of arthritis severity $(P<0.03$, Fig. 3B). Thus, AMC protected mice from the onset of CIA and exhibited therapeutic efficacy against CIA in mice without toxicity or affecting antibody production against collagen.

\section{Effect of AMC on Pro-Inflammatory Cytokine Production in CIA}

Levels of pro-inflammatory cytokines (TNF- $\alpha$ and IL-6) in the serum of immunized mice with and without AMC treatment in the CIA model were compared. In immunized mice not treated with AMC, the TNF- $\alpha$ level increased from day 27 to day 31 and the level remained elevated on day 41 (Fig. 4A). However, the TNF- $\alpha$ level in the mice treated with $\mathrm{AMC}$ at $30 \mathrm{mg} / \mathrm{kg}$ was significantly lower on day 41 than that in the mice not treated with AMC $(p<0.05)$, and the level was similar to the basal level in mock-immunized mice. In immunized mice treated with $\mathrm{AMC}$ at $3 \mathrm{mg} / \mathrm{kg}$, the TNF- $\alpha$ level was also reduced on day 41 although the difference was not statistically significant. On days 27 and 31, a significant reduction of TNF- $\alpha$ levels was not observed in mice treated with $\mathrm{AMC}$ at 3 or $30 \mathrm{mg} / \mathrm{kg}$, although the level of TNF- $\alpha$ was slightly reduced on day 31 in the mice administered AMC at $30 \mathrm{mg} / \mathrm{kg}$. Thus, AMC was effective in reducing the TNF- $\alpha$ level in the severe phase of CIA in a dose-dependent manner.

The IL-6 level decreased from day 27 to day 41 in immunized mice not administered AMC. Administration of AMC at $30 \mathrm{mg} / \mathrm{kg}$ significantly reduced the IL-6 level on days 27 and 31 ( $p<0.05$, Fig. 4B). AMC at $3 \mathrm{mg} / \mathrm{kg}$ also reduced the IL-6 level on day 27, but the reduction was not statistically significant compared with that in the mice not administered AMC $(P=0.058$, Fig. 4B). Thus, AMC was effective in reducing the IL-6 level in the early phase of CIA in a dose-dependent manner.

\section{Effect of AMC on Th1/Th2 Cytokine Production in CIA}

The effects of AMC at $30 \mathrm{mg} / \mathrm{kg}$ on the systemic levels of IFN- $\gamma$ (Th1 cytokine) and IL-10 (Th2 cytokine) were examined during the course of arthritis to evaluate the effect of

Table 1. Effects of AMC in Collagen-Induced Arthritis in DBA/1 Mice ${ }^{\mathrm{a}}$

\begin{tabular}{|c|c|c|c|c|c|c|c|}
\hline Compound & $\begin{array}{c}\text { Dose } \\
(\mathrm{mg} / \mathrm{kg})\end{array}$ & Incidence & $\begin{array}{c}\text { Mean Weight } \\
\text { of } 4 \text { Paws }\end{array}$ & $\begin{array}{c}\text { Mean Number of } \\
\text { Degenerated Joints }\end{array}$ & \multicolumn{3}{|c|}{$\begin{array}{c}\text { Anti-Collagen } \\
\operatorname{IgG}\left(\mathbf{A}_{490}\right)\end{array}$} \\
\hline Mock-immunized mice & & $0 / 5$ & $0.40 \pm 0.01$ & $0.0 \pm 0.0$ & $0.002 \pm 0.002$ & $0.002 \pm 0.002$ & $0.003 \pm 0.001$ \\
\hline \multicolumn{8}{|l|}{ Collagen-immunized mice } \\
\hline AMC & 30 & $2 / 7^{\mathrm{b}}$ & $0.40 \pm 0.01^{\mathrm{b}}$ & $2.4 \pm 0.8^{\mathrm{c}}$ & $0.361 \pm 0.081$ & $0.397 \pm 0.055$ & $0.632 \pm 0.047$ \\
\hline
\end{tabular}

${ }^{\mathrm{a}} \mathrm{AMC}$ at 0 and $30 \mathrm{mg} / \mathrm{kg}$ was orally administered to collagen-immunized DBA1 mice after priming. Incidence, the mean weight of paws and the mean number of degenerated joints of 5 or 7 mice in a group were determined on day 35 after priming.

Sera were prepared on days 27,31 , and 41 , and the amount of anti-collagen type II antibody in sera was determined by ELISA.

Values except Incidence are mean \pm SEM.

${ }^{\mathrm{b}} p<0.05 \mathrm{vs}$. AMC at $0 \mathrm{mg} / \mathrm{kg}$ by Fischer's exact test or Student's $t$-test

${ }^{c} p<0.005$ vs. AMC at $0 \mathrm{mg} / \mathrm{kg}$ by Student's $t$-test. 

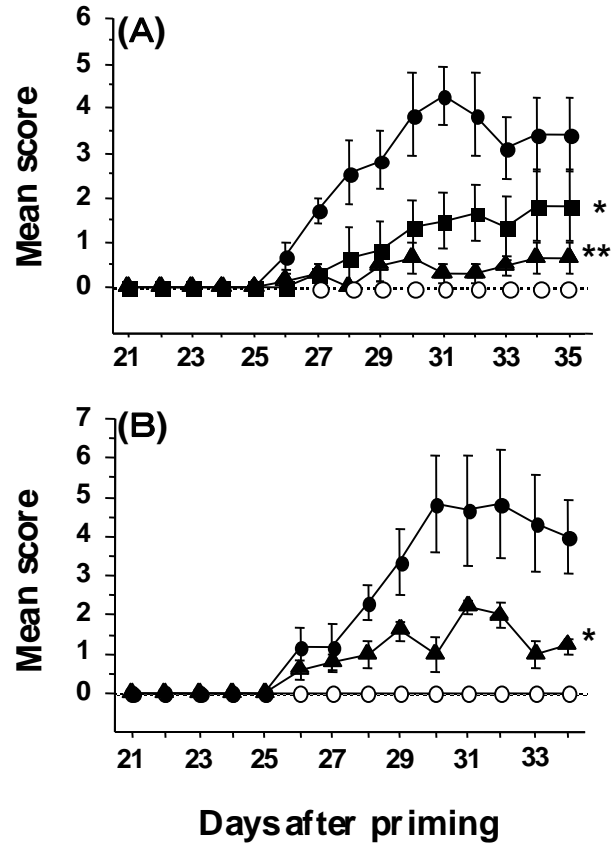

Fig. (3). (A) Prophylactic and therapeutic protection against CIA by AMC. AMC at $0(\bullet), 3(\bullet)$, or $30 \mathrm{mg} / \mathrm{kg}(\boldsymbol{\Delta})$ was orally administered to immunized mice ( $\mathrm{n}=7$ or 8 per group) after priming as described in Materials and Methods. Mock-immunized mice ( $(\circ)$ were administered $5 \%$ gum arabic. Progression scores of diseases are expressed by the mean score \pm SEM of mice in a group. ${ }^{*} p<0.02$ and $* * p<0.002$ vs. AMC at $0 \mathrm{mg} / \mathrm{kg}$ by RM-ANOVA. (B) Therapeutic protection against collagen-induced arthritis by AMC. AMC at $0(\bullet)$ or $30 \mathrm{mg} / \mathrm{kg}(\boldsymbol{\Delta})$ was therapeutically administered to immunized mice ( $n=7$ or 8 per group) from day 27 after the onset of arthritis as described in Materials and Methods. Mock-immunized mice (०) were administered $5 \%$ gum arabic. The development of arthritis is expressed by the mean score \pm SEM. $* p<0.03$ vs. AMC at $0 \mathrm{mg} / \mathrm{kg}$ by RM-ANOVA.

AMC on the changes in the Th1/Th2 immune responses, which are associated with the severity of arthritis. We determined the levels of IFN- $\gamma$ and IL-10 using same serum samples that were used for the determination of proinflammatory cytokine levels (Fig. 4). However, the variations in the levels of IFN- $\gamma$ and IL-10 in each group appeared to be larger than those in the levels of proinflammatory cytokines (Table 2). The larger range may be due to individual differences in mice rather than inappropriate preparation of sera samples. The IFN- $\gamma$ level in immunized mice administered AMC was significantly lower than that in the mice not administered AMC, and the reduced level was similar to that of mockimmunized mice on day 27 ( $p<0.05$, Table 2). On day 31, the IFN- $\gamma$ level in immunized mice administered AMC was also lower than that of immunized mice without AMC although the reduction was not statistically significant. However, no significant reduction of the IL-10 level was observed in AMC-treated mice on days 27 and 31 (Table 2). Thus, AMC at $30 \mathrm{mg} / \mathrm{kg}$ was significantly effective in reducing systemic IFN- $\gamma$ to the basal level in the early phase of CIA.

\section{DISCUSSION AND CONCLUSION}

We evaluated the cytokine-modulatory and therapeutic activities of AMC in a CIA model. AMC suppressed the rise of systemic levels of inducible TNF- $\alpha$, IL-6, and IFN- $\gamma$ and protected mice from CIA. The suppression of TNF- $\alpha$, IL-6, and IFN- $\gamma$ levels correlated with the amelioration of symptoms of arthritis in a dose-dependent manner. Thus, AMC may be a potential therapeutic agent for autoimmune diseases such as RA.

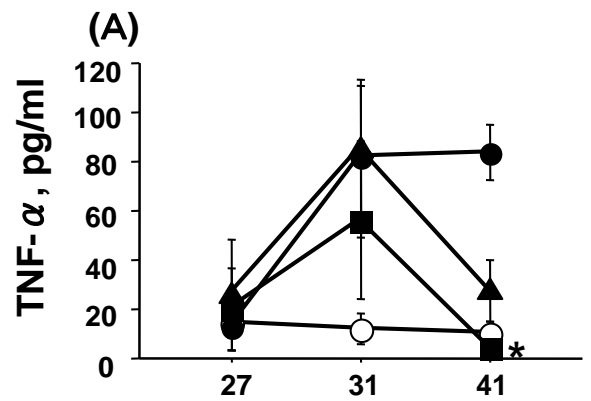

(B)

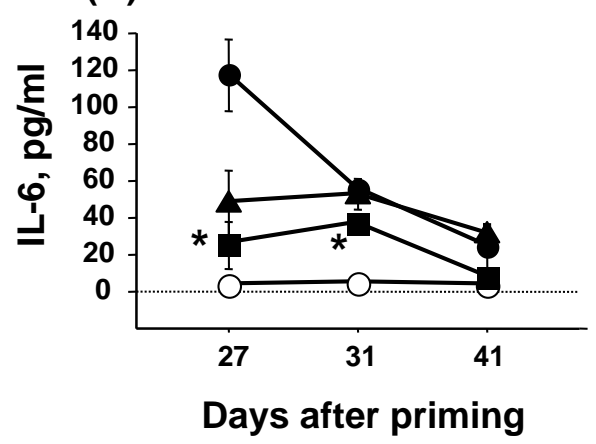

Fig. (4). Suppression of TNF- $\alpha$ (A) and IL-6 (B) production by AMC in mice treated with collagen. AMC at $0(\bullet), 3(\mathbf{A})$, or 30 $\mathrm{mg} / \mathrm{kg}(\boldsymbol{\square})$ was orally administered to immunized mice after priming. Mock-immunized mice (0) were administered 5\% gum arabic. Sera were prepared from 4 to 7 mice in each group on days 27, 31, and 41 after priming. The concentrations of TNF- $\alpha$ (A) and IL-6 (B) in sera are expressed as the mean \pm SEM. ${ }^{*} p<0.05$ vs. mockimmunized mice by Student's $t$-test.

Prophylactic and therapeutic oral administration of AMC at 3 and $30 \mathrm{mg} / \mathrm{kg}$ protected DBA/1 mice from CIA. No significant weight changes of mock-immunized mice were observed due to the oral administration of AMC at $30 \mathrm{mg} / \mathrm{kg}$ compared with control, indicating that AMC is not toxic. $\mathrm{AMC}$ at $30 \mathrm{mg} / \mathrm{kg}$ exerted a significant suppressive action on the swelling of paws in the early phase of arthritis (Table 1). Finally, AMC reduced the incidence of arthritis, and the efficacy of AMC was associated with the protection of joints from severe damage (Table 1). When $30 \mathrm{mg} / \mathrm{kg}$ AMC was orally administered immediately after the onset of arthritis, the severity of arthritis was significantly ameliorated (Fig. 1B). During the development of arthritis in immunized mice, mild inflammation of the joints, manifested as swelling of the paws, developed initially, and then severe deforming arthritis was observed. Thus, AMC appeared to be effective in suppressing the onset of arthritis. The significant reduction in the incidence of arthritis and the significant protection against severe damage might result from suppression of the initial development of arthritis. Therefore, the efficacy of AMC given orally and therapeutically may render it a candidate for the treatment of autoimmune diseases such as RA.

Cytokines, especially pro-inflammatory cytokines, play a pivotal role in the pathology of RA [20]. Their biological 
Table 2. Effects of AMC on IFN- $\gamma$ and IL-10 Levels of Sera of Collagen-Immunized DBA/1 Mice ${ }^{\text {a }}$

\begin{tabular}{|c|c|c|c|c|}
\hline \multirow{2}{*}{ Treatment } & \multicolumn{2}{|c|}{ IFN- $\gamma$ pg/ml } & \multicolumn{2}{c|}{ IL-10 pg/ml } \\
\cline { 2 - 5 } & 27 Days & 31 Days & 27 Days & 31 Days \\
\hline Mock-immunized mice & $4.7 \pm 0.3$ & $4.7 \pm 0.3$ & $81.6 \pm 68.6$ & $139.9 \pm 55.1$ \\
\hline Collagen-immunized mice & & & $95.6 \pm 51.1$ & $1012.7 \pm 118.7$ \\
\hline AMC $\quad 0 \mathrm{mg} / \mathrm{kg}$ & $47.3 \pm 14.1$ & $148.7 \pm 36.8$ & $86.9 \pm 23.0$ & $1034.1 \pm 121.9$ \\
\hline AMC $30 \mathrm{mg} / \mathrm{kg}$ & $5.3 \pm 0.4^{\mathrm{b}}$ & $79.3 \pm 52.8$ & & \\
\hline
\end{tabular}

${ }^{\mathrm{a}} \mathrm{AMC}$ at 0 and $30 \mathrm{mg} / \mathrm{kg}$ was orally administered to collagen-immunized mice.

On days 27 and 31 after priming, sera were prepared from 5 mice in each group.

The IL-10 and IFN- $\gamma$ levels in the sera are expressed as the mean \pm SEM.

b $p<0.05$ vs. AMC at $0 \mathrm{mg} / \mathrm{kg}$ by Student's $t$-test.

actions appear to contribute to acute and chronic inflammation, cell proliferation, and tissue destruction/fibrosis in the pathology of RA. IL-6 plays a key role in the development of arthritis [16,17]. A high level of IL-6 was observed in both the serum and synovial fluids of RA patients [20] and was suggested to be useful marker for RA activity [21]. In this study, AMC at $30 \mathrm{mg} / \mathrm{kg}$ significantly suppressed the rise in the IL-6 level in serum at the onset of CIA (Fig. 2B), and the suppression correlated with the reduction in the severity of arthritis. In our murine CIA model, the systemic IL-6 level was higher at the onset of CIA than at the phase of severe arthritis, and this high level was significantly suppressed by AMC to the level of the control mice (Fig. 2B). Thus, the efficacy of AMC was related to the systemic suppression of the IL-6 level in mice. Further, the administration of AMC from the onset of mild inflammatory arthritis significantly reduced the severity of CIA (Fig. 1B). AMC was suggested to inhibit the onset of CIA, possibly by suppressing the elevation of IL-6 levels at the initiation of arthritis. The diseasepromoting role of TNF- $\alpha$ in RA has been well established [22], and agents that reduce levels of systemic TNF- $\alpha$ are in clinical use [23]. TNF- $\alpha$ is easily detectable in synovial fluid $[24,25]$, and many investigators have demonstrated the worsening of CIA following treatment with TNF- $\alpha$ [26,27]. The systemic TNF- $\alpha$ level was higher in the late phase of CIA than at the onset in our murine CIA model, and the high level was significantly suppressed to the level of control mice by AMC (Fig. 2A). AMC might also contribute to suppression of the severity of CIA. Previously we showed that a coumarin derivative, 7-hydroxycoumarin, reduced the rise of the systemic IL-1 $\alpha$ level in influenza virus-infected mice and exhibited an antipyretic effect but did not inhibit cyclooxygenase activity and fever induction in IL- $1 \alpha$-injected mice, in contrast to aspirin [7,9]. This suggested that the antiinflammatory activity of coumarin derivatives might not be like that of aspirin. Thus, the AMC action suppressing the elevated cytokine level might be independent of antiinflammatory activity.

IL-6 acts locally and systemically as a stimulator of not only B cell function but also $\mathrm{T}$ cell function [28]. The severity of CIA is associated with a strong Th1 type response with a high level of IFN- $\gamma$ and negligible production of Th2 type cytokines such as IL-4 and IL-10 [29]. IFN- $\gamma$ has been suggested to be a key factor mediating susceptibility to
CIA [30]. When we examined the effect of AMC on the levels of IFN- $\gamma$ and IL-10, Th1 and Th2 cytokines, respectively, in serum during arthritis, the IFN- $\gamma$ level was significantly reduced in AMC-treated mice at the onset of arthritis, while no significant reduction of the IL-10 level was observed (Table 2). This is consistent with the report that the severity of CIA was not associated mainly with the production of Th2 type cytokines [29]. Further, the level of anticollagen IgG in serum was not significantly affected by AMC administration (Table 1). Thus, AMC might weaken the Th1 immune response at the onset of arthritis and contribute to the significant reduction of the incidence and progression of CIA.

AMC significantly reduced systemic levels of IL-6, TNF$\alpha$, and IFN- $\gamma$ in the CIA model (Figs. $\mathbf{2 A}$ and $\mathbf{B}$ and Table 2). Previously, AMC was shown to inhibit transcription of IL$1 \alpha$, TNF- $\alpha$, and IL- 6 in lipopolysaccharide-treated murine macrophage-like P388D1 cells [13]. In a murine endotoxin shock model, AMC administration suppressed the rise of IL6 and TNF- $\alpha$ levels in serum [13], but it did not affect the basal levels of IL-1 $\alpha$, TNF- $\alpha$, and IL-6 in normal mice [13]. Thus, the differences may be due to the inducing stimuli, the target cells, and their sensitivity to AMC. AMC may have a novel ability to modulate cytokine levels only in response to specific stimuli without affecting the basal levels.

In this study, we demonstrated that AMC exhibited therapeutic efficacy against CIA. The results presented here suggest that the cytokine-suppressive activity of AMC is associated with its efficacy. AMC reduced the rise of systemic levels of IL-6, TNF- $\alpha$, and IFN- $\gamma$ to their basal levels in the serum of normal mice (Fig. $\mathbf{2 A}$ and $\mathbf{B}$ and Table $\mathbf{2}$ ). $\mathrm{AMC}$ is a cytokine modulator specific to inducible cytokines, especially pro-inflammatory cytokines, in cytokinemediated diseases, and may be a potential therapeutic agent for cytokine-mediated diseases.

\section{ACKNOWLEDGMENTS}

We thank Dr. M. Tsurita, Ms. T. Okuda, Ms. A. Hino, and Mr. Y. Yoshida for their excellent technical assistance. We also thank Ms. Katherine Ono for her editorial assistance. This study was partly supported by Grants-in-Aid (No. 18590129 and 20590131) from the Japan Society for the Promotion of Science and Health and Labour Sciences Re- 
search Grants (Research on Risk of Chemical Substances) from the Ministry of Health, Labour and Welfare of Japan.

\section{REFERENCES}

[1] Guerne, A.P.; Zuraw, B.L.; Vaughan, J.H.; Carson, D.A.; Lotz, M. Synovium as a source of interleukin-6 in vivo. Contribution to local and systemic manifestations of arthritis. J. Clin. Invest., 1989, 83, 585-592.

[2] Marsh, C.B.; Wewers, M.D. The pathogenesis of sepsis: Factors that modulate the response to Gram-negative bacterial infection. Clin. Chest Med., 1996, 7, 183-197.

[3] Parrillo, J.E. Pathogenic mechanisms of septic shock. N. Engl. J. Med., 1993, 328, 1471-1477.

[4] Ross, S.E.; Williams, R.O.; Mason, L.J.; Mauri, C.; MarinovaMutafchieva, L.; Malfait, A-M.; Maini, R.N.; Feldmann, M. Suppression of TNF- $\alpha$ expression, inhibition of Th1 activity, and amelioration of collagen-induced arthritis by rolipram. J. Immunol., 1997, 159, 6253-6259.

[5] Thorbecke, G.J.; Shah, R.; Leu, C.H.; Kuruvilla, A.P.; Hardison, A.M.; Palladio, M.A. Involvement of endogeneous tumor necrosis factor $\alpha$ and transforming growth factor $\beta$ during induction of collagen type II arthritis in mice. Proc. Natl. Acad. Sci. USA, 1992, 89, 7375-7379.

[6] Tracey, K.J.; Fong, Y.; Hesse, D.G.; Manogu,e K.R.; Lee, A.T.; Kuo, G.C.; Lowry, S.F.; Cerami, A. Anti-cachectin/TNF monoclonal antibodies prevent septic shock during lethal bacteraemia. Nature, 1987, 330, 662-664.

[7] Kurokawa, M.; Imakita, M.; Kumeda, C.A.; Shiraki, K. Cascade of fever production in mice infected with influenza virus. J. Med. Virol., 1996, 50, 152-158.

[8] Kurokawa, M.; Imakita, M.; Kumeda, C.A.; Yukawa, T.A.; Shiraki, K. Kakkon-to suppressed interleukin-1 $\alpha$. production responsive to interferon and alleviated influenza infection in mice. $J$. Tradit. Med., 1996, 13, 201-209.

[9] Kurokawa, M.; Kumeda, C.A.; Yamamura, J.; Kamiyama, T.; Shiraki, K. Antipyretic activity of cinnamyl and related compounds in Kakkon-to, a traditional medicine, in influenza virus-infected mice. Eur. J. Pharm., 1998, 348, 45-51.

[10] Kurokawa, M.; Yamamura, J.; Li, Z.; Sato, H.; Hitomi, N.; Tatsumi, Y.; Shiraki K. Antipyretic activity of components with regulatory activity of interleukin- $1 \alpha$ production in Gingyo-san, a traditional medicine, in influenza virus-infected mice. Chem. Pharm. Bull., 1998, 46, 1444-1447.

[11] Tsurita, M.; Kurokawa, M.; Imakita, M.; Fukuda, Y.; Watanabe, Y.; Shiraki, K. Early augmentation of interleukin (IL)-12 level in the airway of mice administered orally with clarithromycin or intranasally with IL-12 results in alleviation of influenza infection. $J$. Pharmacol. Exp. Ther., 2001, 298, 362-368.

[12] Kurokawa, M.; Tsurita, M.; Brown, J.; Fukuda, Y.; Shiraki, K. Effect of interleukin-12 level augmented by Kakkon-to, an herbal medicine, on the early stage of influenza infection in mice. Antiviral Res., 2002, 56, 183-188.

[13] Kurokawa, M.; Brown, J.; Kagawa, Y.; Shiraki, K. Cytokineregulatory activity and therapeutic efficacy of cinnamyl derivatives in endotoxin shock. Eur. J. Pharm., 2003, 474, 283-293.

[14] Williams, R.O.; Mason, L.J.; Feldmann, M.; Maini, R.N. Synergy between anti-CD4 and anti-TNF in the amelioration of established collagen-induced arthritis. Proc. Natl. Acad. Sci. USA, 1994, 91, 2762-2766.
[15] Moreland, L.W.; Baumgartne, S.W.; Schiff, M.H.; Tindall, E.A.; Fleischmann, R.M.; Weaver, A.L.; Ettlinger, R.E.; Cohen, S.; Koopman, W.J.; Mohler, K.; Widmer, M.B.; Blosch, C.M. Treatment of rheumatoid arthritis with a recombinant human tumor necrosis factor receptor (p75)-Fc fusion protein. N. Engl. J. Med., 1997, 337, 141-147.

[16] Alonzi, T.; Fattori, E.; Lazzaro, D.; Costa, C.; Probert, L.; Kollias, G.; De Benedetti, F.; Poli, V.; Ciliberto, G. Interleukin 6 is required for the development of collagen-induced arthritis. J. Exp. Med., 1998, 187, 461-468.

[17] Ohshima, S.; Saeki, Y.; Mima, T.; Sasai, M.; Nishioka, K.; Nomura, S.; Kopf, M.; Katada, Y.; Tanaka, T.; Suemura, M.; Kishimoto, T. Interleukin-6 plays a key role in the development of antigen-induced arthritis. Proc. Natl. Acad. Sci. USA, 1998, 95, 822282226.

[18] Inaba, T.; Tanaka, K.; Takeno, R.; Nagaki, H.; Yoshida, C.; Takano, S. Synthesis and antiinflammatory activity of 7-methanesulfonylamino-6-phenoxychromones. Antiarthritic effect of the 3formylamino compound (T-614) in chronic inflammatory disease models. Chem. Pharm. Bull., 2000, 48, 131-139.

[19] Nagasaka, K.; Kurokawa, M.; Imakita, M.; Terasawa, K.; Shiraki, K. Efficacy of Kakkon-to, a traditional herb medicine, in herpes simplex virus type 1 infection in mice. J. Med. Virol., 1995, 46, 2834.

[20] Feldmann, M.; Brennan, F.M.; Maini, R.N. Role of cytokines in rheumatoid arthritis. Annu. Rev. Immunol., 1996, 14, 397-440.

[21] Houssiau, F.A.; Devogelaer, J.P.; Van Damme, J.; de Deuxchaines, C.N.; Van Snick, J. Interleukin-6 in synovial fluid and serum of patients with rheumatoid arthritis and other inflammatory arthritides. Arthritis Rheum., 1998, 31, 784-788.

[22] Feldmann, M.; Maini, R.N. Anti-TNF alpha therapy of rheumatoidarthritis: what have we learned? Annu. Rev. Immunol., 2001, 19, 163-196.

[23] Macias, I.; Garcia-Perez, S.; Ruiz-Tudela, M.; Medina, F.; Chozas, N.; Giron-Gonzalez, J.A. Modification of pro- and antiinflammatory cytokines and vascular-related molecules by tumor necrosis factor- $\alpha$ blockade in patients with rheumatoid arthritis. $J$. Rheumatol., 2005, 32, 2102-2108.

[24] Di Giovine, F.S.; Nuki, G.; Duff, G.W. Tumour necrosis factor in synovial exudates. Ann. Rheum. Dis., 1988, 47, 768-772.

[25] Saxne, T.; Palladino, M.A. Jr.; Heinegard, D.; Talal, N.; Wollheim, F.A. Detection of tumor necrosis factor alpha but not tumor necrosis factor beta in rheumatoid arthritis synovial fluid and serum. Arthritis Rheum., 1988, 31, 1041-1045.

[26] Cooper, W.O.; Fava, R.A.; Gates, C.A.; Crèmer, M.A.; Townes, A.S. Acceleration of onset of collagen-induced arthritis by intraarticular injection of tumour necrosis factor or transforming growth factor-beta. Clin. Exp. Immunol., 1992, 89, 244-250.

[27] Brahn, E.; Peacock, D.J.; Banquerigo, M.L.; Liu, D.Y. Effects of tumor necrosis factor alpha (TNF-alpha) on collagen arthritis. Lymphokine Cytokine Res., 1992, 11, 253-256.

[28] Robak, T.; Gladalska, A.; Stepien, H.; Robak, E. Serum levels of interleukin-6 type cytokines and soluble interleukin-6 receptor in patients with rheumatoid arthritis. Mediators Inflamm., 1998, 7, 347-353.

[29] Van Snick, J. Interleukin-6: an overview. Annu. Rev. Immunol., 1990, 8, 253-278.

[30] Chu, C-Q.; Song, Z.; Mayton, L.; Wu, B.; Wooley, P.H. IFN- $\gamma$ deficient $\mathrm{C} 57 \mathrm{BL} / 6\left(\mathrm{H}-2^{\mathrm{b}}\right)$ mice develop collagen induced arthritis with predominant usage of T cell receptor V 36 and Vß8 in arthritic joints. Ann. Rheum. Dis., 2003, 62, 983-990. 